\title{
Positive expiratory pressure plateau breathing in spontaneously breathing patients with myocardial infarction and pulmonary œdema
}

\author{
FINLAY KERR, DAVID J. EWING, JOHN B. IRVING, \\ MICHAEL F. SUDLOW, and BRIAN J.KIRBY \\ Department of Medicine, University of Edinburgh, Royal Infirmary, Edinburgh
}

\begin{abstract}
Kerr, F., Ewing, D. J., Irving, J. B., Sudlow, M. F., and Kirby, B. J. (1974). Thorax, 29, 690-694. Positive expiratory pressure plateau breathing in spontaneously breathing patients with myocardial infarction and pulmonary oedema. The respiratory effects of breathing with a positive expiratory pressure plateau (PEPP) was studied in 24 spontaneously breathing, alert, nonsedated patients with pulmonary oedema following myocardial infarction. When 20 patients breathed room air with PEPP a small rise in arterial oxygen tension $\left(\mathrm{PaO}_{2}\right)$ with a fall in alveolar to arterial oxygen gradient $\left(\mathrm{A}-\mathrm{aDO}_{2}\right)$ occurred. Arterial carbon dioxide tension did not change significantly. When PEPP was used in six patients after breathing $100 \%$ oxygen for 20 minutes there was no significant change in $\mathrm{PaO}_{2}, \mathrm{~A}-\mathrm{aDO}_{2}$ or anatomical shunt $\left(\mathbf{Q}_{\mathrm{S}} / \mathbf{Q}_{\mathrm{T}}\right)$. Expired air collection in a further six of the patients demonstrated that although PEPP produced an increase in tidal volume $\left(V_{T}\right)$, alveolar ventilation $\left(V_{A}\right)$ fell slightly as a result of a decrease in respiratory rate, and oxygen consumption $\left(\mathrm{Vo}_{2}\right)$ did not change.

In 10 normal subjects functional residual capacity (FRC), measured continuously in a whole-body volume displacement plethysmograph, decreased by a small amount when these subjects breathed with PEPP.

Positive expiratory pressure plateau breathing in spontaneously breathing conscious patients with pulmonary oedema produced a small improvement in ventilation/perfusion matching not by an increase in FRC but by an increase in $V_{T}$. The increase in $V_{T}$ probably altered the ventilation/perfusion relationships by a redistribution of inspired gas.
\end{abstract}

In 1944 Barach advocated positive expiratory pressure as a means of clearing oedema from the lungs of spontaneously breathing patients. This received little attention until recently when positive expiratory pressure was reported to improve arterial oxygenation in patients with acute respiratory failure who were already receiving intermittent positive pressure ventilation (IPPV) (Ashbaugh, Bigelow, Petty, and Levine, 1967; McIntyre, Laws, and Ramachandran, 1969; Kumar et al., 1970; Falke et al., 1972). When used to treat pulmonary oedema in spontaneously breathing anaesthetized dogs a favourable increase in arterial oxygen tension was similarly found (Lysons and Cheyney, 1972). We therefore decided to evaluate positive expiratory pressure as an adjunct to the treatment of pulmonary oedema following myocardial infarction in conscious alert spontaneously breathing patients.
Recent studies refer to positive expiratory pressure? whether used in patients receiving IPPV (Kumar et al., 1970; Falke et al., 1972) or in spontaneouslyg breathing dogs (Lysons and Cheyney, 1972) as positive end expiratory pressure (PEEP) when in fact the positive pressure is present throughoun the expiratory phase of the respiratory cycle. For this? reason we have preferred to use the term positives expiratory pressure plateau (PEPP), as suggested by McIntyre et al. (1969).

\section{METHODS}

PATIENTS We studied 24 patients $(20$ men, 4 women) aged between 37 and 76 years (mean 57 years) who suffered from myocardial infarction complicated by pulmonary oedema. Myocardial infarction was diagnosed by history $\Omega$ accepted electrocardiographic criteria, and a diagnostic rise in serum creatine phosphokinase. Each patient had 
bilateral basal pulmonary crepitations which persisted after coughing, and radiographic evidence of pulmonary oedema varying from pulmonary venous congestion alone to septal lines and alveolar oedema. The chest radiographs were portable films with a tube film distance of $180 \mathrm{~cm}$ taken in full inspiration with the patient sitting upright. Thirteen of the patients smoked more than five cigarettes daily, but none was subject to recurrent bronchitis. At the time of the study there was no clinical nor radiographic evidence of chest infection or pulmonary embolus. None of the patients had required opiate therapy in the 12-hour period before the study. We also studied 10 normal healthy subjects (8 men, 2 women) aged between 19 and 40 years, one of whom was a cigarette smoker. All subjects agreed to take part after a full explanation of the procedure involved.

PROCEDURE The patients with pulmonary oedema were studied when semirecumbent. They breathed through a rubber mouthpiece and non-rebreathing valve (Collins, J. Valve, dead space $92 \mathrm{ml}$ ), the nose being occluded by a clip. A positive expiratory pressure plateau was produced by immersing a wide-bore tube from the expiratory port of the valve in water to a depth of 5 or $10 \mathrm{~cm}$ in a Winchester flask. Arterial blood was sampled through a Longdwel $6 \mathrm{~cm} 18$ gauge Tefion cannula inserted percutaneously under local anaesthesia in the brachial artery 20 minutes before the study began.

Twenty patients breathed with an expiratory pressure plateau of $5 \mathrm{~cm}$ of water for 3 minutes. In preliminary studies a steady state was achieved within three minutes. FRC fluctuated for the first half minute and thereafter remained stable. The patients were able to maintain PEPP for 3 minutes without undue effort. Arterial blood was sampled just before and at the end of the pressure breathing and in 13 patients 5 minutes after stopping pressure breathing. In nine patients the procedure was repeated at an expiratory pressure plateau of $10 \mathrm{~cm}$ of water for 3 minutes following a 15-minute recovery period. Another six of the patients breathed $100 \%$ oxygen for 20 minutes through a reservoir bag attached to the inspiratory port of the valve and then breathed with an expiratory pressure plateau of $10 \mathrm{~cm}$ of water for 3 minutes while continuing to breath oxygen. Arterial blood was sampled just before and at the end of pressure breathing.

In the 10 normal subjects the functional residual capacity (FRC) was measured continuously in a wholebody volume displacement plethysmograph (Mead, 1960) while breathing at zero expiratory pressure for 5 minutes and at an expiratory pressure plateau of $5 \mathrm{~cm}$ and $10 \mathrm{~cm}$ of water, each for a period of 3 minutes, allowing 15 minutes' recovery between each as in the patient protocol. To determine that there was no spirometer drift during the measurement, after 3 minutes the subject exhaled to residual volume and then immediately inspired to total lung capacity. In all cases the vital capacity measured by this manoeuvre was identical $( \pm 50 \mathrm{ml})$ with the vital capacity measured before the expiratory pressure was applied. The measurements were repeated in two of the subjects measuring intrathoracic pressure with an oesophageal balloon and mouth pressure with a latera pressure tap close to the mouthpiece. Following three maximal inspirations static deflation pressure volume curves were recorded by standard techniques (MilicEmili, Mead, Turner, and Glauser, 1964) during periods of breathing at end-expiratory pressure plateaux of zero, $5 \mathrm{~cm}$, and $10 \mathrm{~cm}$ of water.

ANALYTICAL METHODS Arterial blood gas tensions and pH were measured immediately after sampling with Radiometer equipment $\left(\mathrm{PO}_{2}\right.$ electrode type E5044, $\mathrm{PCO}_{2}$, electrode type E5036 and pH microelectrode type E5021 calibrated with tonometered blood (Flenley, Millar, and Rees, 1967)).

The expired gas volumes were measured by a Tissot spirometer and corrected to body temperature, pressure, saturated with water (BTPS). Mixed expired $\mathrm{CO}_{2}$ was measured by a Uras III infrared $\mathrm{CO}_{2}$ analyser (Patrick, 1963) and inspired and expired oxygen concentrations by a Servomex OA 101 Mark II paramagnetic analyser (Ellis and Nunn, 1968).

CAlCulations Oxygen saturation was derived from $\mathrm{Po}_{2}$ and $\mathrm{pH}$, by the Severinghaus blood gas calculator (Severinghaus, 1966) and oxygen capacity calculated from the patient's haemoglobin. Venous admixture $\left(\hat{Q}_{v_{A}} / \dot{Q}_{T}\right)$ was calculated by the standard shunt equation

$$
\dot{\mathrm{QV}}_{\mathrm{VA}} / \dot{\mathrm{Q}}_{\mathrm{T}}=\frac{\mathrm{CCO}_{2}-\mathrm{CaO}_{2}}{\mathrm{CCO}_{2}-\mathrm{CV}_{\mathbf{2}}}
$$

where $\mathrm{CCO}_{2}, \mathrm{CaO}_{2}$ and $\mathrm{Cv}_{2}$ are the oxygen contents of pulmonary end capillary blood, arterial blood, and mixed venous blood. The equation was amended for calculation of anatomical shunt $\left(\dot{Q}_{\mathbf{S}} / \dot{Q}_{\mathbf{T}}\right)$ when the patients breathed $100 \%$ oxygen

$$
\dot{\mathrm{Q}}_{\mathrm{S}} / \dot{Q}_{\mathrm{T}}=\frac{\left(\mathrm{PAO}_{2}-P \mathrm{PaO}_{2}\right) 0.003}{5+\left(\mathrm{PAO}_{2}-P \mathrm{PO}_{2}\right) 0.003} \times 100
$$

where $P_{\mathrm{AO}_{2}}$ is alveolar oxygen tension and 0.003 the solubility coefficient for oxygen in whole blood. $\mathbf{Q}_{\mathbf{V}} / \mathbf{Q}_{\mathbf{T}}$ and $\dot{Q}_{\mathrm{s}} / \dot{Q}_{\mathrm{T}}$ were expressed as a percentage of cardiac output. In the shunt calculations we assumed a fixed arteriovenous oxygen content difference of 5 volumes per $100 \mathrm{ml}$. End pulmonary capillary $\mathrm{PO}_{2}$ was considered equal to $\mathrm{PAO}_{2}$ which was calculated from the alveolar air equation

$$
P_{\mathrm{AO}_{2}}=\mathrm{PIO}_{2}-\mathrm{PACO}_{2}\left(\mathrm{FIO}_{2}+\frac{1-\mathrm{FIO}_{2}}{\mathrm{R}}\right)
$$

where $\mathrm{PIO}_{2}$ is inspired oxygen tension, $\mathrm{PACO}_{2}$ alveolar carbon dioxide tension, and $\mathrm{FrO}_{2}$ the fractional concentration of $\mathrm{O}_{2}$ in inspired gas. $\mathrm{PACO}_{2}$ was considered equal to $\mathrm{PaCO}_{2}$. The gas exchange ratio (R) was measured in six patients and the mean (Table II) was used to calculate $P_{\mathrm{AO}_{2}}$ in the other patients.

The significance of the results was assessed by Student's paired $t$ test. Results in the tables and text are represented as means \pm SEM.

\section{RESULTS}

The changes in the arterial oxygenation of 20 patients produced by breathing with an expiratory pressure plateau of $5 \mathrm{~cm}$ of water are illustrated by the Figure. 


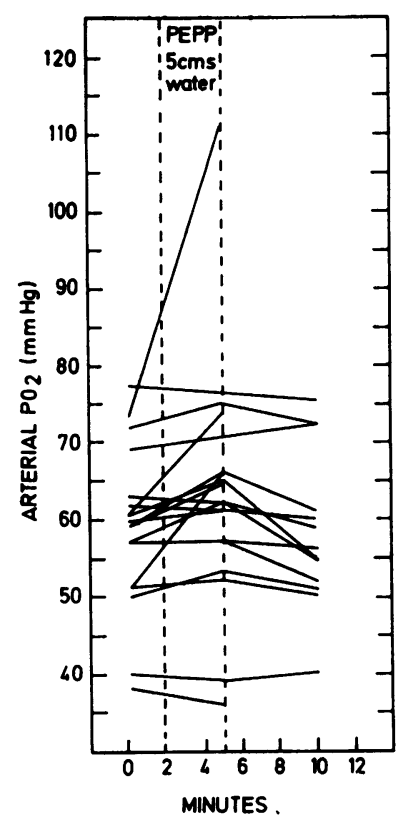

FIGURE Positive expiratory pressure plateau (PEPP) breathing in 20 patients with pulmonary oedema.

In 18 of the patients the $\mathrm{PaO}_{2}$ when breathing air, before PEPP, was below $70 \mathrm{mmHg}$ and five were markedly hypoxic with a $\mathrm{PaO}_{2}$ less than $52 \mathrm{mmHg}$. Although a meaningful rise in $\mathrm{PaO}_{2}$ was found in only half of the patients, three of them had a striking rise ranging from $13 \mathrm{mmHg}$ to $39 \mathrm{mmHg}$. The mean rise in $\mathrm{PaO}_{2}(5 \mathrm{mmHg})(\mathrm{P}<0.05)$ was not associated with a significant change in the $\mathrm{PaCO}_{2}$ or $\left[\mathrm{H}^{+}\right]$. The venous admixture $\left(\mathrm{Q}_{\mathrm{VA}} / \mathrm{Q}_{\mathrm{T}}\right)$ fell by $4 \%$
$(\mathrm{P}<0.02)$ and alveolar to arterial oxygen gradient $\frac{0}{0}$ $\left(\mathrm{A}-\mathrm{aDO}_{2}\right)$ by $8 \mathrm{mmHg}(\mathrm{P}<0.001)$ (Table I). Increasing the expiratory pressure plateau from $5 \mathrm{~cm} \overline{\bar{c}}$. water to $10 \mathrm{~cm}$ water in nine of the patients did not $\widehat{\Phi}$ significantly alter the $\mathrm{PaO}_{2}$.

The ventilatory effects, studied in six patients, of an ${ }^{\text {के }}$ expiratory pressure plateau of $10 \mathrm{~cm}$ water are shown $\vec{\circ}$ in Table II. The respiratory rate fell from $25 \pm 2=$ breaths/minute to $15 \pm 1$ breaths/minute $(P<0.01) \omega$ and although tidal volume $\left(V_{T}\right)$ increased from $\overrightarrow{\vec{F}}$ $490 \pm 73 \mathrm{ml}$ to $679 \pm 111 \mathrm{ml}(\mathrm{P}<0.01)$ minute ventilation $\left(\mathbf{V}_{\mathbf{E}}\right)$ fell. Alveolar ventilation $\left(\mathbf{V}_{\mathbf{A}}\right)$ fell by a .0 proportionately smaller amount while dead space? $\left(V_{D}\right)$ remained unchanged. There was no noticeable $\subseteq$ increase in the energy requirements of breathing with PEPP as judged by the absence of a significant ${ }_{-}$ increase in oxygen consumption $\left(\mathrm{Vo}_{2}\right)$.

When six patients breathed with an expiratory? pressure plateau of $10 \mathrm{~cm}$ water after breathing $100 \% \frac{\Phi}{3}$ oxygen for 20 minutes there was no significanto change in $\mathrm{PaO}_{2}$ or shunt $\left(\mathbf{Q}_{\mathrm{S}} / \mathbf{Q}_{\mathrm{T}}\right)$ (Table III).

In our 10 normal subjects measurements of FRC $\vec{\varphi}$ before PEPP were constant but with PEPP there were $\$$ initially fluctuations in FRC which settled after $30^{\circ}$ seconds. Measurements made over the last $30 \bigcirc$ seconds of a three-minute period of quiet breathing with PEPP showed a consistent and reproduciblea pattern (Table IV). In three subjects (1-3) there were no significant changes in FRC with PEPP; five $\stackrel{\varrho}{\rightarrow}$ subjects (4-8) showed a fall in FRC with increasing PEPP; only two subjects ( 9 and 10$)$ showed a rise and then not at each level of PEPP. The mean fall in FRC at each level was small, $5 \mathrm{~cm}$ water $-360 \mathrm{ml}(\mathrm{P}<0.02)$ and $10 \mathrm{~cm}$ water $-560 \mathrm{ml}(\mathrm{P}<0.01)$. Static elastic $\vec{\circ}$ recoil of the lung over the vital capacity range was studied in two of the subjects (4 and 9). Their deflation:.

T A B L E I

POSITIVE EXPIRATORY PRESSURE PLATEAU (PEPP) BREATHING IN 20 PATIENTS WITH PULMONARY OEDEMA

\begin{tabular}{|c|c|c|c|c|c|}
\hline Expiratory Pressure & $\mathrm{PaO}_{2}$ & $\mathrm{PaCO}_{2}$ & {$\left[\mathrm{H}^{+}\right]$} & Qva/QT & $\mathrm{A}-\mathrm{aDO}_{\mathbf{3}}$ \\
\hline $\begin{array}{l}0 \mathrm{~cm} \text { water } \\
5 \mathrm{~cm} \text { water } \\
\text { Significance }\end{array}$ & $\begin{array}{c}59 \pm 2 \\
64 \pm 3 \\
P<0.05\end{array}$ & $\begin{array}{c}35 \pm 1 \\
35 \pm 1 \cdot 5 \\
\mathrm{NS}\end{array}$ & $\begin{array}{c}38 \pm 1 \\
37 \pm 1 \\
\text { NS }\end{array}$ & $\begin{array}{c}25 \pm 3 \\
21 \pm 3 \\
\mathrm{P}<0.02\end{array}$ & $\begin{array}{c}46 \pm 3 \\
38 \pm 3 \\
P<0.001\end{array}$ \\
\hline
\end{tabular}

'Mean \pm SEM.

NS $=$ not significant.

T A B L E I I

POSITIVE EXPIRATORY PRESSURE PLATEAU (PEPP) BREATHING IN SIX PATIENTS WITH PULMONARY OEDEMA1

\begin{tabular}{|c|c|c|c|c|c|c|c|c|}
\hline $\begin{array}{c}\text { Expiratory } \\
\text { Pressure }\end{array}$ & $\begin{array}{c}\text { Respiratory } \\
\text { Rate } \\
\text { (breaths/min) }\end{array}$ & $\begin{array}{c}\text { Minute } \\
\text { Ventilation } \\
(1 / \mathrm{min})\end{array}$ & $\begin{array}{c}\text { Alveolar } \\
\text { Ventilation } \\
(1 / \mathrm{min})\end{array}$ & $\begin{array}{c}\text { Tidal Volume } \\
\text { (VT) } \\
\text { (ml) }\end{array}$ & $\begin{array}{c}\text { Dead Space } \\
\text { (VD) } \\
\text { (ml) }\end{array}$ & VD/VT $\%$ & $\begin{array}{c}\text { Oxygen } \\
\text { Consumption } \\
(\mathrm{ml} / \mathrm{min})\end{array}$ & $\underset{\substack{\text { Gas } \\
\text { Ratio }}}{\text { Range }}$ \\
\hline $\begin{array}{l}0 \mathrm{~cm} \text { water } \\
10 \mathrm{~cm} \text { water } \\
\text { Significance }\end{array}$ & $\begin{array}{l}25 \pm 2.0 \\
15 \pm 1.0 \\
(P<0.01)\end{array}$ & $\begin{array}{c}14 \pm 1.5 \\
10.6 \pm 1.0 \\
(P<0.001)\end{array}$ & $\begin{array}{l}5.7 \pm 0.88 \\
5.1 \pm 0.84 \\
(P<0.02)\end{array}$ & $\begin{array}{l}490 \pm 73 \\
679 \pm 111 \\
(P<0.01)\end{array}$ & $\begin{array}{c}246 \pm 26 \\
291 \pm 28 \\
\text { NS }\end{array}$ & $\begin{array}{l}52 \pm 3 \cdot 0 \\
46 \pm 4 \cdot 5 \\
=\mathrm{NS}\end{array}$ & $\begin{array}{c}263 \pm 18 \\
270 \pm 21 \\
\text { NS }\end{array}$ & $\begin{array}{c}0.8 \pm 0.04 \\
0.7 \pm 0.04 \\
\text { NS }\end{array}$ \\
\hline
\end{tabular}

'Mean \pm SEM.

NS $=$ not significant. 


\section{T A B L E I I I}

$100 \%$ OXYGEN BREATHING AND POSITIVE EXPIRATORY PRESSURE PLATEAU (PEPP) BREATHING IN SIX PATIENTS WITH PULMONARY OEDEMA ${ }^{1}$

\begin{tabular}{l|c|c|c|c}
\hline \multicolumn{1}{c|}{$\begin{array}{c}\text { Expiratory } \\
\text { Pressure }\end{array}$} & $\mathrm{PaO}_{2}$ & $\mathrm{PaCO}_{2}$ & {$\left[\mathrm{H}^{+}\right]$} & Qs/QT \\
\cline { 2 - 4 } $\begin{array}{l}\text { 0 cm water } \\
\text { breathing air }\end{array}$ & $62 \pm 7$ & $39 \pm 2$ & $37 \pm 1 \cdot 5$ & \\
$\begin{array}{l}0 \mathrm{~cm} \text { water } \\
\text { breathing 100\% O, } \\
\text { for 20 min }\end{array}$ & $399 \pm 53$ & $38 \pm 2$ & $37 \pm 2$ & $14 \pm 2.5$ \\
$\begin{array}{l}10 \text { cm water } \\
\text { breathing 100\% O, }\end{array}$ & $445 \pm 47$ & $41 \pm 2$ & $39 \pm 2$ & $11 \pm 2$ \\
Significance & $\mathrm{NS}$ & $\mathrm{NS}$ & $\mathrm{P}<0.05$ & $\mathrm{NS}$ \\
\hline
\end{tabular}

'Mean + SEM.

NS $=$ not significant

T A B L E I V

FRC (LITRES) IN NORMAL SUBJECTS DURING ZERO EXPIRATORY PRESSURE BREATHING AND TWO LEVELS OF POSITIVE EXPIRATORY PRESSURE PLATEAU BREATHING ${ }^{1}$

\begin{tabular}{|c|c|c|c|}
\hline \multirow[b]{2}{*}{ Subject } & \multicolumn{3}{|c|}{ Expiratory Pressure } \\
\hline & $0 \mathrm{~cm}$ Water & $5 \mathrm{~cm}$ Water & $10 \mathrm{~cm}$ Water \\
\hline $\begin{array}{r}1 \\
2 \\
3 \\
4 \\
5 \\
6 \\
7 \\
8 \\
9 \\
10\end{array}$ & $\begin{array}{l}4.2 \\
2.9 \\
3.5 \\
3.2 \\
5.0 \\
3.0 \\
4.0 \\
3.4 \\
4.4 \\
3.5\end{array}$ & $\begin{array}{l}4 \cdot 1 \\
2 \cdot 7 \\
3 \cdot 0 \\
2 \cdot 7 \\
4 \cdot 2 \\
2 \cdot 6 \\
2 \cdot 8 \\
3 \cdot 0 \\
4 \cdot 4 \\
3 \cdot 9\end{array}$ & $\begin{array}{l}4 \cdot 1 \\
2 \cdot 7 \\
3.5 \\
2 \cdot 1 \\
4 \cdot 0 \\
2.0 \\
2.6 \\
2.2 \\
4 \cdot 7 \\
3 \cdot 5\end{array}$ \\
\hline Mean & $3 \cdot 7 \pm 0 \cdot 21$ & $3 \cdot 34 \pm 0.23$ & $3 \cdot 14 \pm 0 \cdot 30$ \\
\hline Significance & & $<0.02$ & $<0.01$ \\
\hline
\end{tabular}

${ }^{1}$ Mean \pm SEM.

pressure-volume curves were within normal range (Turner, Mead, and Wohl, 1968) and showed no change when repeated towards the end of a threeminute period of positive expiratory pressure plateau breathing at both $5 \mathrm{~cm}$ and $10 \mathrm{~cm}$ of water.

\section{DISCUSSION}

A positive expiratory pressure was originally thought to clear pulmonary oedema by increasing intraalveolar pressure above pulmonary capillary pressure (Barach, Martin, and Eckman, 1938). Subsequent work suggests that correction of hypoxia in these patients may not relate entirely to clearance of oedema fluid from the lungs. Peribronchial oedema accumulating in the earliest stages of pulmonary oedema (Staub, Nagano, and Pearce, 1967) is thought to cause narrowing and closure of small airways (Hughes and Rosenzweig, 1970) with consequent maldistribution of ventilation and mismatching of ventilation and blood flow. A rise in arterial oxygen tension has been produced by adding an expiratory pressure plateau to patients with acute respiratory failure receiving IPPV (Ashbaugh et al., 1967; McIntyre et al., 1969; Kumar et al., 1970; Falke et al., 1972).

A similar rise in arterial oxygen tension was produced when PEPP was applied to spontaneously breathing anaesthetized dogs with experimentally induced pulmonary oedema (Lysons and Cheyney, 1972). In these studies the improvement in gas exchange was attributed to prevention of closure of small airways by a rise in FRC. The increase in FRC results in an increased transpulmonary pressure during tidal breathing. This increased transpulmonary pressure will mean an increased transbronchial pressure which could prevent closure of small airways. However, in spontaneously breathing normal subjects we found that PEPP did not produce an increase in FRC. This differs from the findings when PEPP is used in patients receiving IPPV (McIntyre et al., 1969; Kumar et al., 1970; Falke et al., 1972). There are probably two reasons for this. When PEPP is added while patients are receiving IPPV a different situation is created since inspiration is already assisted and the addition of PEPP produces a continuous positive pressure in the airways throughout the respiratory cycle (CPPV). It seems that assisted inspiration is of importance in achieving and maintaining a higher FRC when PEPP is added. Secondly, those patients received respiratory depressant drugs which would counteract any tendency to return FRC actively to its former level by the voluntary use of expiratory muscles. This may also explain the findings of Lysons and Cheyney (1972) that spontaneously breathing dogs develop a rise in FRC with PEPP when the anaesthetic used would prevent the voluntary use of expiratory muscles decreasing the FRC. Thus it seems that conscious, alert, spontaneously breathing, nonsedated subjects fail to develop an increase in FRC because inspiration is unassisted and the expiratory muscles are used to return FRC to or below its former level.

The small rise in $\mathrm{PaO}_{2}$ and fall in alveolar to arterial oxygen gradient and venous admixture in our patients suggest that some improvement in pulmonary ventilation/perfusion matching did occur. In the light of the findings in normal subjects it is unlikely that this is due to a rise in FRC. It is, however, evident that PEPP does alter the pattern of ventilation, producing a decrease in respiratory rate with a fall in minute ventilation but a rise in tidal volume. Increasing the tidal volume produces more uniform distribution of ventilation in normal subjects (Ball, Stewart, Newsham, and Bates, 1962) and furthermore has been shown to increase $\mathrm{PaO}_{2}$ in patients with pulmonary oedema following 
myocardial infarction (Saunders, 1965; Higgs, 1968).

To rule out the possibility of PEPP opening already closed gas-exchanging units we repeated the procedure in patients breathing oxygen. Any excess shunt remaining after breathing $100 \%$ oxygen for an adequate time is due to perfusion of unventilated alveoli. If PEPP opened up such areas a fall in the percentage shunt would be expected. This did not happen and therefore improved distribution of ventilation occurred without the reversal of atelectatic areas.

We did not set out to measure the circulatory responses to PEPP in spontaneously breathing subjects but others have done so (Werko, 1947; Gillick and Schneider, 1949; Lysons and Cheyney, 1972) and their work suggests that an expiratory pressure plateau of 5 to $10 \mathrm{~cm}$ of water has no major effect. The changes in gas exchange are unlikely to be due to an overall alteration in perfusion, but we cannot rule out an improvement in the distribution of pulmonary perfusion.

The increase in $\mathrm{PaO}_{2}$ produced by PEPP was disappointingly small and is best explained by the finding that in alert conscious subjects PEPP produces not an increase in FRC but a modest rise in tidal volume. Although a rise in tidal volume does produce more uniform distribution of ventilation (Ball et al., 1962) and may improve matching of ventilation to perfusion the rise found in our patients was small. Larger increases in tidal volume may produce a greater rise in $\mathrm{PaO}_{2}$ and could reverse atelectasis as suggested by Saunders (1965) and Higgs (1968). However, such increases in tidal volume can be produced more simply without PEPP by a voluntary increase in the depth of breathing.

Thus, while PEPP is of value in the management of hypoxic patients on mechanical ventilators, we have found it of limited value in spontaneously breathing patients with pulmonary oedema.

We are grateful to Professor K. W. Donald for his encouragement, to Dr. D. C. Flenley and Dr. A. L. Muir for much helpful discussion, and to the technical, nursing, and secretarial staff for their willing assistance. J.B.I. was a British Heart Foundation Junior Research Fellow.

\section{REFERENCES}

Ashbaugh, D. G., Bigelow, D. B., Petty, T. L., and Leevine, B. E. (1967). Acute respiratory distress in adults. Lancet, 2, 319.

Ball, W. C., Stewart, P. B., Newsham, L. G. S., and Bates, D. V. (1962). Regional pulmonary function studied with xenon ${ }^{138}$. Journal of Clinical Investigation, 41, 519.

Barach, A. L. (1944). Principles and Practices of Inhalational Therapy, p. 52. Lippincott, Philadelphia.

_-, Martin, J., and Eckman, M. (1938). Positive pressure respiration and its application to the treatment of acute pulmonary edema. Annals of Internato Medicine, 12, 754.

Ellis, F. R. and Nunn, K. F. (1968). The measurement of gaseous oxygen tension utilizing paramagnetism: an evaluation of the 'Servomex' OA.150 analyzer.'s British Journal of Anaesthesia, 40, 569.

Falke, K. J., Pontoppidan, H., Kumar, A., Leith, D. E. Geffin, B., and Laver, M. B. (1972). Ventilation with $\vec{\omega}$ end-expiratory pressure in acute lung disease. $\%$ Journal of Clinical Investigation, 51, 2315.

Flenley, D. C., Millar, J. S., and Rees, H. A. (1967). Accuracy of oxygen and carbon dioxide electrodes. British Medical Journal, 2, 349.

Gillick, F. G. and Schneider, J. (1949). Electrokymo-8 graphic studies of lung field pulsations with exhalation against pressure. Journal of Applied Physiology, 2, 30.으

Higgs, B. E. (1968). Factors influencing pulmonary gas exchange during the acute stages of myocardial $Z$ infarction. Clinical Science, 35, 115.

Hughes, J. M. B. and Rosenzweig, D. Y. (1970). Factors $\stackrel{\Phi}{\square}$ affecting trapped gas volume in perfused dog lungs. Journal of Applied Physiology 29, 332.

Kumar, A., Falke, K. J., Geffin, B., Aldredge, C. F., $\vec{\bullet}$ Laver, M. B., Lowenstein, E., and Pontopiddan, $H$. (1970). Continuous positive-pressure ventilation in acute respiratory failure: effects on hemodynamics? and lung function. New England Journal of Medicine, 283, 1430.

Lysons, D. F. and Cheyney, F. W. (1972). End-expiratoryo pressure in dogs with pulmonary edema breathing spontaneously. Anesthesiology, 37, 518.

McIntyre, R. W., Laws, A. K., and Ramachandran, P. R. $\overrightarrow{\vec{O}}$ (1969). Positive expiratory pressure plateau. Canadian 3 Anaesthetists' Society Journal, 16, 477.

Mead, J. (1960). Volume displacement body plethysmo-O graph for respiratory measurements in human subjects. Journal of Applied Physiology, 15, 736.

Milic-Emili, J., Mead, J., Turner, J. M., and Glauser, E. M. (1964). Improved technique for estimating pleural pressure from esophageal balloons. Journal of Applied Physiology, 19, 207.

Patrick, J. M. (1963). Calibration of an infra-red $\mathrm{CO}_{2} \stackrel{\AA}{\AA}$ meter for measurement of alveolar $\mathrm{PCO}_{2}$. Journal of $₹$ Physiology, 169, 74P.

Saunders, K. B. (1965). Alveolar-arterial gradient for oxygen in heart-failure. Lancet, 2, 160.

Severinghaus, J. W. (1966). Blood gas calculator. Journal of Applied Physiology, 21, 1108.

Staub, N. C., Nagano, H., and Pearce, M. L. (1967). Pulmonary edema in dogs, especially the sequence of 0 fluid accumulation in lungs. Journal of Applied Physiology, 22, 227.

Turner, J. M., Mead, J., and Wohl, M. E. (1968). Elasticity of human lungs in relation to age. Journal of Applied Physiology, 25, 664.

Werko, L. (1947). The influence of positive pressure $\stackrel{?}{+}^{+}$ breathing on the circulation in man. Acta Medica 0 Scandinavica, 128, Supplement, 193, p. 75.

Requests for reprints to Dr. F. Kerr, Department of $\frac{\mathcal{Q}}{\mathbb{D}}$ Medicine, University of Edinburgh, Royal Infirmary,으 Edinburgh, EH3, 9YW. 